\title{
Principles, Milestones and Interventions for Early Years of Human Growth and Development: An Insight
}

\author{
Ritu Singh*, Niharika Bisht and Huma Parveen
}

AICRP-CD, Deptt. of Human Development and Family Studies, College of Home Science, G.B.P.U.A.\&T., Pantnagar-263145, Uttarakhand, India

*Corresponding author

Keywords

Domains of

Development,

Educational Games,

Heredity,

Maturation

Article Info

Accepted:

04 May 2019

Available Online:

10 June 2019

\section{A B S T R A C T}

\section{Introduction}

Change has always been the essence of life. The moment a life is conceived, the process of growth and development begins. It is this process that enables a child to change from being a highly dependent to an independent one. The terms 'growth' and 'development' are often used interchangeably however they are different concepts. Growth means an increase in size, height, weight, length etc. which can be quantified whereas development implies qualitative changes like changes in skill, abilities that results in improved day to day functioning. It involves a series of progressive, orderly and meaningful changes leading to the goals of maturity. Development is a broader term as it refers to overall changes in the individual. In true sense, development in its quantitative aspect is termed as growth. Growth is something which discontinues after reaching maturity but development goes throughout the lifespan of an individual. For eg. a child may grow very fast in terms of height, weight but it cannot be considered development in the sense of advancement to a higher level of maturity. Right after the conception, a child goes through a process of rapid growth and development. This enables the child to 
acquire certain skills and abilities that later influence his/her interaction with the environment. As early childhood period is considered to be one of the most critical developmental phase, an understanding of how growth and development occurs in early years and what are the various dimensions of development is of prime importance

\section{Areas of development}

\section{Physical development}

The physical development includes growth in size and in proportion along with muscle coordination and control. For example a five months old child learning to roll over, lift head, etc.

\section{Cognitive development}

This is the child's ability to learn and solve problems. For example, this includes a twomonth-old baby learning to explore the environment with hands or eyes or a three year old learning how to memorize poem.

\section{Speech and language development}

This is the child's ability to both understand and use language. For example, this includes a 12-month-old baby saying his first words, a two-year-old naming parts of her body.

\section{Social development}

A child learning and discovering the expectations and rules for interacting with others. Examples: a child smiling at mother, a child involved in cooperative play.

\section{Emotional development}

The ability to recognize and understand feelings and how to respond to them appropriately. Example: a child feeling insecure at the arrival of a new baby in the family, a child being afraid of the dark.

\section{Moral development}

The growing understanding of right and wrong, and the change in behavior caused by that understanding.

\section{Principles of growth and development}

There are definite and predictable patterns in growth and development that are continuous, orderly, and progressive. These patterns sometimes referred to as trends or principles, are universal and basic to all human beings. The principles are discussed as under (Ruffin 2019; Palmer 1960; Sharma \& Tomar 2005; Introduction to growth and development 2011 $\&$ Principles of child development 2017)

Development involves change: Development involves a progressive series of changes. Right from conception to the time of death, the person undergoes numerous changes. It implies both quantitative and qualitative changes.

Development is a continuous process: Development continues throughout the life of an individual. It starts at conception and lasts till death. One stage of development lays the foundation for the next stage of development. For egg: at first stage child has limited knowledge but as he moves to the next stage he acquires new information through explorations and assimilates and accommodates it thereby forming the basis for further achievement and the process continues.

Development proceeds from general to specific: Development occurs from large muscle movements to more refined muscle movements. For eg. An infant will grasp beads by using the whole hand but eventually he learns to use the thumb and forefinger to do the same. 
Development is sequential: Development always occurs in an orderly manner and follows certain sequences. For example, all children first learn to scribble before they write. Similarly, they learn to draw a line before attempting to draw a circle.

Development is predictable: Every stage has some common traits and characteristics. aspects of development occur in predictable, orderly patters. Experts can roughly predict when certain milestones should occur. The difference in physiological and psychological potentialities can be predicated by observation and psychological test.

\section{Development proceeds in 'specific' directions (cephalocaudal \&} proximodistal): Development occurs in specific direction. Development that proceeds from the head to toe is known as cephalocaudal. According to it, development will first take place in the head region and then will proceed downwards. For example a child first learns to gain control of his head followed by arms and legs.

Also it is evident that coordination of arms always precedes coordination of legs. Because at first the child lifts themselves up by using their arms and later they are able to gain leg control and may be able to crawl, stand, or walk.

Another principle that describes the direction of development is proximodistal. According to it, development proceeds from centre to periphery. For example the child's arms develop before the hands and the hands and feet develop before the fingers. For eg. A child first learns to wave hands before learning to hold a crayon to scribble or draw.

Development is a product of interaction of the heredity and environment: A child's genetic inheritance (i.e., heredity) provides the basic foundation for many physical and personality attributes, but the influences of social, cultural, and familial variables (i.e., environment) also contribute to development. Neither heredity nor environment can alone affect the development of an individual. The two simultaneously hand in hand right from the conceptions.

Development depends on maturation and learning: Maturation refers to the sequential characteristic of biological growth and development. The biological changes occur in sequential order and give children new abilities. Changes in the brain and nervous system account largely for maturation. These changes in the brain and nervous system help children to improve in thinking and motor skills. Also, children must mature to a certain point before they can progress to new skills. For example, a four-month-old cannot use language because the infant's brain has not matured enough to allow the child to talk. By two years old, the brain has developed further and with help from others, the child will have the capacity to say and understand words.

There are individual rates of growth and development: Each one is different and unique and the rates at which development takes place also differ at individual level. Although the patterns and sequences for growth and development are usually the same for all children, the rates at which children reach developmental stages will be different. For example some children learn to walk very early while others don't. These are individual differences.

\section{Understanding developmental milestones}

In the first few years of life, the growth of a child is very rapid, and then it slows down later. Development is often interpreted by the attainment developmental milestones. Developmental milestones are a set of behaviors, skills, or abilities that are demonstrated by specified ages during 
infancy and early childhood in typical development (Beighley \& Matson 2013). According to the Centers for Disease Control and Prevention-CDC (2010) following are some of the developmental milestones:

\section{Two months}

\section{Social and emotional}

Begins to smile at people

Can briefly calm herself (may bring hands to mouth and suck on hand)

Tries to look at parent

\section{Language/Communication}

Coos, makes gurgling sounds

Turns head toward sounds

\section{Cognitive (learning, thinking, problem- solving)}

Pays attention to faces

Begins to follow things with eyes and recognize people at a distance

Begins to act bored (cries, fussy) if activity doesn't change

\section{Movement/Physical Development}

Can hold head up and begins to push up when lying on tummy

Makes smoother movements with arms and legs

\section{Four months}

\section{Social and emotional}

Smiles spontaneously, especially at people

Likes to play with people and might cry when playing stops

Copies some movements and facial expressions, like smiling or frowning

\section{Language/Communication}

Begins to babble
Babbles with expression and copies sounds he hears

Cries in different ways to show hunger, pain, or being tired

Cognitive (learning, thinking, problemsolving)

Lets you know if he is happy or sad

Responds to affection

Reaches for toy with one hand

Uses hands and eyes together, such as seeing a toy and reaching for it

Follows moving things with eyes from side to side

Watches faces closely

Recognizes familiar people and things at a distance

\section{Movement/Physical development}

Holds head steady, unsupported

Pushes down on legs when feet are on a hard surface

May be able to roll over from tummy to back

Can hold a toy and shake it and swing at dangling toys

Brings hands to mouth

\section{Six months}

\section{Social and emotional}

Knows familiar faces and begins to know if someone is a stranger

Likes to play with others, especially parents

Responds to other people's emotions and often seems happy

Likes to look at self in a mirror

\section{Language/Communication}

Responds to sounds by making sounds

Strings vowels together when babbling ("ah," "eh," "oh") and likes taking turns with parent while making sounds

Responds to own name 
Makes sounds to show joy and displeasure Begins to say consonant sounds (jabbering with "m," "b")

Cognitive (learning, thinking, problemsolving)

Looks around at things nearby

Brings things to mouth

Shows curiosity about things and tries to get things that are out of reach

Begins to pass things from one hand to the other

\section{Movement/Physical Development}

Rolls over in both directions (front to back, back to front)

Begins to sit without support

When standing, supports weight on legs and might bounce

Rocks back and forth, sometimes crawling backward before moving forward

Nine months

\section{Social and emotional}

May be afraid of strangers

May be clingy with familiar adults

Has favorite toys

\section{Language/Communication}

Understands "no"

Makes a lot of different sounds like "mamamama" and "bababababa"

Copies sounds and gestures of others

Uses fingers to point at things

\section{Cognitive (learning, thinking, problem-} solving)

Watches the path of something as it falls

Looks for things she sees you hide

Plays peek-a-boo

Puts things in his mouth

Moves things smoothly from one hand to the other
Picks up things like cereals between thumb and index finger

\section{Movement/Physical development}

Stands, holding on

Can get into sitting position

Sits without support

Pulls to stand

Crawls

\section{2 months}

\section{Social and emotional}

Is shy or nervous with strangers

Cries when mom or dad leaves

Has favorite things and people

Shows fear in some situations

Hands you a book when he wants to hear a story

Repeats sounds or actions to get attention

Puts out arm or leg to help with dressing

Plays games such as "peek-a-boo" and "pat-acake"

\section{Language/Communication}

Responds to simple spoken requests Uses simple gestures, like shaking head "no" or waving "bye-bye"

Makes sounds with changes in tone (sounds more like speech)

Says "mama" and "dada" and exclamations like "uh-oh!"

Tries to say words you say

Cognitive (learning, thinking, problemsolving)

Explores things in different ways, like shaking, banging, throwing

Finds hidden things easily

Looks at the right picture or thing when it's named

Copies gestures

Starts to use things correctly; for example, 
drinks from a cup, brushes hair

Bangs two things together

Puts things in a container, takes things out of a container

Lets things go without help

Pokes with index (pointer) finger

Follows simple directions like "pick up the toy"

\section{Movement/Physical development}

Gets to a sitting position without help

Pulls up to stand, walks holding on to furniture ("cruising")

May take a few steps without holding on

May stand alone

\section{8 months}

\section{Social and Emotional}

Likes to hand things to others as play

May have temper tantrums

May be afraid of strangers

Shows affection to familiar people

Plays simple pretend, such as feeding a doll

May cling to caregivers in new situations

Points to show others something interesting

Explores alone but with parent close by

\section{Language/Communication}

Says several single words

Says and shakes head "no"

Points to show someone what he wants

\section{Cognitive (learning, thinking, problem-} solving)

Knows what ordinary things are for; for example, telephone, brush, spoon

Points to get the attention of others

Shows interest in a doll or stuffed animal by

pretending to feed

Points to one body part

Scribbles on his own

Can follow 1-step verbal commands without any gestures; for example, sits when you say "sit down"

\section{Movement/Physical development}

Walks alone

May walk up steps and run

Pulls toys while walking

Can help undress herself

Drinks from a cup

Eats with a spoon

\section{4 months}

\section{Social and emotional}

Copies others, especially adults and older children

Gets excited when with other children

Shows more and more independence

Shows defiant behavior (doing what he has been told not to)

Plays mainly beside other children, but is beginning to include other children, such as in chase games

\section{Language/Communication}

Points to things or pictures when they are named

Knows names of familiar people and body parts

Says sentences with 2 to 4 words

Follows simple instructions

Repeats words overheard in conversation

Points to things in a book

Cognitive (learning, thinking, problemsolving)

Finds things even when hidden under two or three covers

Begins to sort shapes and colors

Completes sentences and rhymes in familiar books

Plays simple make-believe games

Builds towers of 4 or more blocks

Might use one hand more than the other

Follows two-step instructions such as "Pick 
up your shoes and put them in the closet."

Names items in a picture book such as a cat, bird, or dog .

\section{Movement/Physical development}

Stands on tiptoe

Kicks a ball

Begins to run

Climbs onto and down from furniture without help

Walks up and down stairs holding on

Throws ball overhand

Makes or copies straight lines and circles

It is often said that home is the first school of a child where he begins the process of learning and parents are his first teachers. Hence, it becomes very important for parents to understand the principles and milestones of child development in order to understand the developmental needs of the child. This understanding can help parents know whether child is achieving the milestones of development on time or he needs some additional support. It is important from developmental perspective because once parents have a fairly good idea of child development they are able to provide stimulus and engage child in age appropriate activities in home. Also the knowledge of child development helps parents to have reasonable expectations from children. Keeping this in mind, the research team of AICRP- CD pantnagar has designed few activities for parents to understand some fundamentals of child development that could help them provide a better developmental foundation to their children.

\section{Activity 1 'Building Blocks'}

\section{Time}

15-20 minutes approximately (Depends on number of respondents)

\section{Material required}

Blocks (Fig. 1).

\section{How to play}

Put 10-15 blocks in front of all.

Ask each of them to come one by one and arrange the blocks in a building but put two blocks in inverse position (as shown in Fig. 2).

Ask everyone to come and make it.

See for how long they are able to make a building successfully.

At the end of the activity, tell them a principal of development that 'Development is sequential'. It cannot take place in any different manner.

Demonstrate to them that if they would have placed the blocks in right order (not following the inverse order), they could have made a comparatively longer structure.

Tell them that in same manner development always follows a sequence. Give them some examples like unless a child learns to stand, he cannot learn to walk.

Ask them to volunteer and give some more examples.

Applaud everyone for participation.

\section{Activity 2"What happens first"}

Time

25-30 minutes (Depends on numbers of respondents)

\section{Material}

A clipboard having two contours of human body drawn over it, with developmental milestones written at correct parts of the body (milestones related to a particular body part as shown in Fig. 3).

Number chits

Thumb pins 


\section{How to play}

Place the clipboard in front of respondents.

Ask them to read or read to them all the milestones.

Give them 5 minutes to think about the correct sequence of the milestones in ascending order.

Now, ask them to come one by one and give them the number chits to ascend the milestones by placing ascending numbers over each milestone with the help of thumb pins.

Repeat the activity with all.

At the end of the activity, explain them about how development proceeds in specific directions like cephalocaudal and proximodistal. Give examples

Ask them to volunteer to give some examples. Applaud everyone for participation
Fig.1

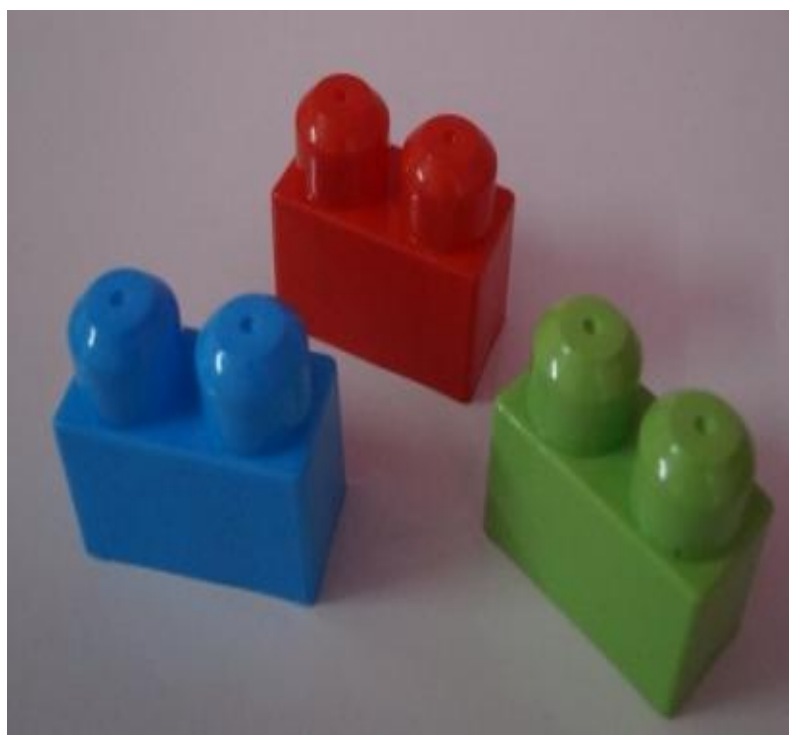

Fig.2

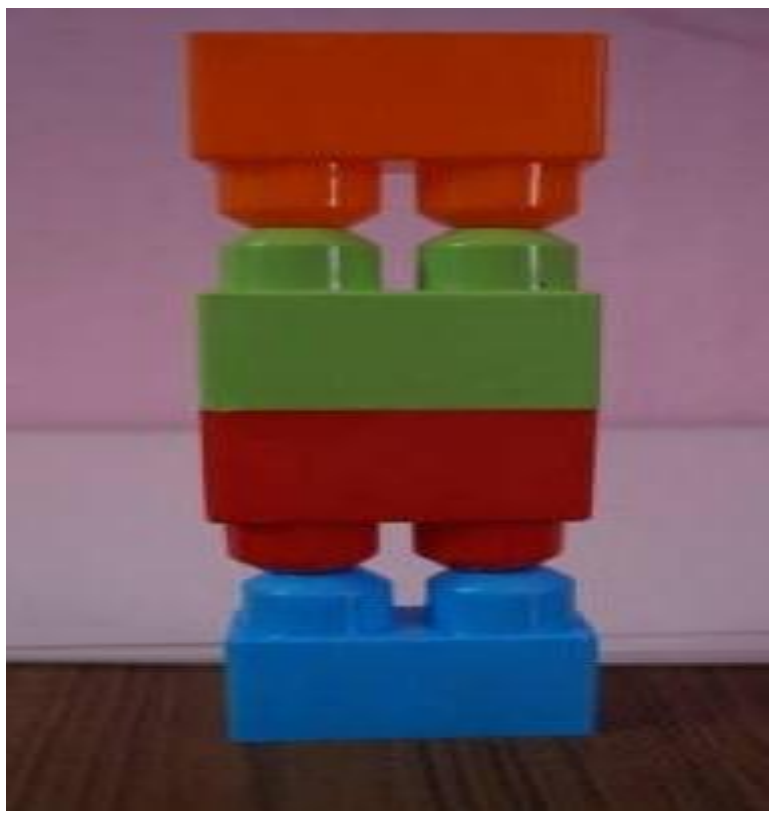


Fig.3

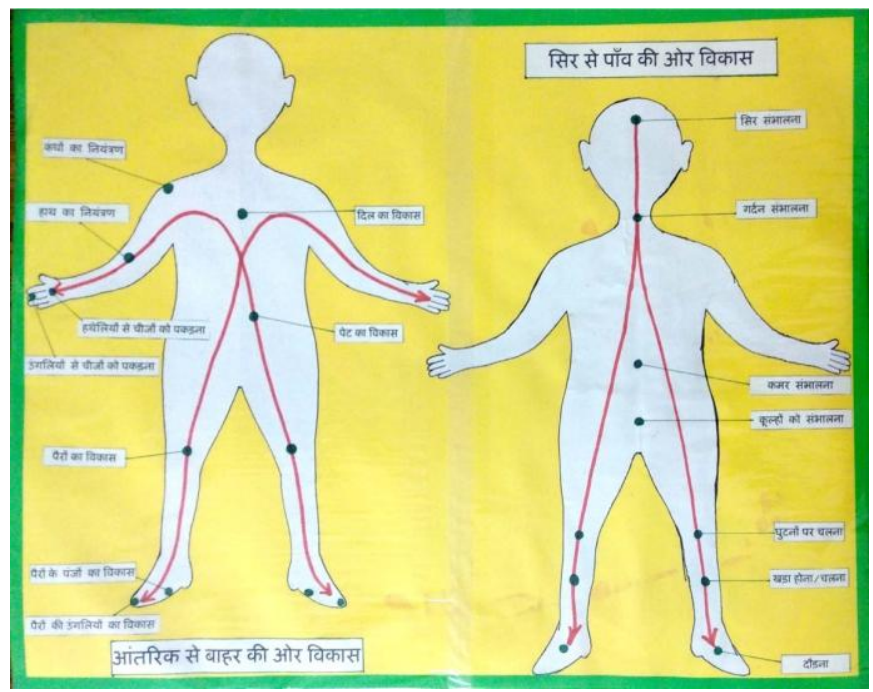

In conclusion, human development is a lifelong process of physical, social, cognitive and emotional changes. Early years of life are considered very critical as they serve as the foundation of a healthy development. Hence, the insight into the fundamentals of child development becomes very necessary because it helps us to understand how a child develops, why they develop the way they do and what can be done to help them develop effectively. As parents play a very instrumental role in the development for their child therefore they must be equipped with knowledge concerning the basics of child development so that they become better parents. We as a society must also put efforts to optimize the early years of children's lives to ensure their future success.

\section{References}

Beighley J.S., Matson J.L. (2013) Developmental Milestones. In: Volkmar F.R. (eds) Encyclopedia of Autism Spectrum Disorders. Springer, New York.

Centers for Disease Control and Prevention. (2010). Learn the signs. Act early. Retrieved May 8, 2019, from http://www.cdc.gov/ncbddd/acte arly/milestones/

Hurlock E.B.(1978).Child Growth and Development, Tata Mcgraw-Hill Publishing Company LTD. 5th Edition, New Delhi, India

Introduction to Growth and Development (2011) Retrieved May 7, 2019 from http://www.kkhsou.in/main/education/ growth.html

Palmer C (1960). Principles of child growth and development. Journal of Education Research, 53 (7), 273-275.

Principles of Child Development (2017) Retrieved on 5 May, 2019 from http://www.edugyan.in/2017/02/princi ples-of-child-development.html

Ruffin N (2019) Human Growth and Development - A Matter of Principles. Virginia Cooperative Extension, Virginia Tech, Virginia.

Sharma S and Tomar M (2005) Principles of Growth and Development. Isha Books, New Delhi, India. Page 55-59.

What is child development (2008) Retrieved on May 5, 2019 from http://www.howkidsdevelop.com/deve lopSkills.html 


\section{How to cite this article:}

Ritu Singh, Niharika Bisht and Huma Parveen. 2019. Principles, Milestones and Interventions for Early Years of Human Growth and Development: An Insight. Int.J.Curr.Microbiol.App.Sci. 8(06): 181-190. doi: https://doi.org/10.20546/ijcmas.2019.806.022 